\title{
Environmental Impact Assessment (EIA) of Gas Pipeline Transmission (Case Study: Duzduzan - Ahar)
}

\section{SAEED KARIMI ${ }^{1}$, FATEMEH SADAT ALAVIPOOR ${ }^{1,2 *}$, NEGAR FOROUGHI ${ }^{2}$, MEHRDAD NAHAVANDCHI ${ }^{2}$ and ABDOLHOSSEIN KHAKIAN ${ }^{2}$}

\author{
University of Tehran, Faculty of Environment, Department of Environmental Planning, \\ Management and Education. No 15, Qods St., Enghelab Ave. Tehran, Iran.
}

http://dx.doi.org/10.12944/CWE.9.3.17

(Received: September 24, 2014; Accepted: November 10, 2014)

\begin{abstract}
The national gas transmission Ahar - Duzduzan, transmit fresh gas in the West north of Iran. According to Iran's environmental regulation, construction and operation of pipelines is required EIA studies. Due to this linear project it is required to develop a particular EIA methodology on this kind of projects. Therefore at first we attempted to get a real knowledge about environmental endnotes of project with library and field studies. Along with reviewing the technical resources of the project, attempted to identify all of the construction and operation activities. Finally two methods of explanatory checklist and simplified matrix selected for EIA. In The construction phase 19 micro activities have evaluated in front of about 12 environmental factors (in the various environments). In the construction phase, activities such as; excavation, embankment and excavation show the greatest negative impact on the whole environment of area. And the most important activity with positive effects on the aforementioned factors is manpower recruitment. Also In the operation phase 15 micro activities have evaluated in front of about 15 environmental factors (in the various environments). In the Operation phase activities such as; grazing, vehicle traffic and wastewater production can have negative effects. Most positive impacts on environmental factors are revenue and welfare, employment levels, commerce and manning activities, immigration control and air quality. Most of the Operation phase effects are positive which involve; exploitation of gas or natural gas transportation and gas pipeline monitoring. According to the developed methodology it is necessary to use RS and GIS tools in the study current environment situation, routing environmental alternatives and make land use maps of transmission path. With regard to all issues presented in explanatory checklist of this project and also previous clauses from the standpoint of environmental compliance provisions there isn't any problem for implementation.
\end{abstract}

Key word: EIA, gas transmission, Ahar, Duzduzan, environment, GIS.

\section{INTRODUCTION}

Iran has 22 thousand kilometers of gas pipeline and has the longest gas and oil pipelines in the Middle East.it also has the third largest consumption of natural gas in the world after United States and Russia. At present, Iran is producing only a small share of its gas reserves, about 5.5 trillion cubic feet (160 billion cubic meters) per year. This means that Iran is one of the few countries capable of supplying much larger amounts of natural gas in the future. (Book: Iran Oil Ministry Annual Bulletin, 5th Edition, pages 190-193). In this regard, in order to prevent wasting some of gas resources in future, construction of gas pipe line transmission is necessary that it's the most economical and least effective method. An important issue here will occur is environmental impact, safety and health due to the pipeline development.in other words, much of industry development requires, scientifically and predictive target planning based on safety, health and environmental variables ${ }^{1}$. Environmental Impact Assessments (EIAs) are widely accepted as an effective tool for predicting changes in environmental conditions and setting up environmental management programs and its benefits are well accepted ${ }^{2,3,4,5,6,7}$. The aim of the EIA is to determine, to forecast, to assess and to propose measures for mitigation 
of the environmental impacts associated with the proposals for implementation, the decision making for implementation of the Investment Proposal and with assuming the respective commitments ${ }^{8}$. Environmental assessments of such projects which are classified as a linear project, in many technical and methodological aspects are different from other projects. Therefore developing an appropriate methodology for such projects seems necessa.$^{1}$ Jozi and Iran khahi in $2010^{\circ}$, have studied purpose of environmental risk assessment for gas transportation pipelines, combined the indexing system method and Analytical Hierarchy Process. For the purpose of examining results of this research, environmental risk assessment of gas transportation pipelines 24 inches for Tasuj-Salmas with approximate length about 42 kilometer as a case study was exerted. Salehi moayad and karimi in $2007^{1}$, have studied environmental impact assessment for gas transportation pipelines of Hamedan-Bijar, by GIS \& RS method. Papadopoulou and Antoniou ${ }^{10}$ have studied different alternative locations for the construction and operation of a liquefied natural gas (LNG) terminal station in Cyprus were evaluated, explicitly considering also their connection to the power generation station of Mari and the country's gateway. Sosa and Alvarez-Ramirez (2009) ${ }^{11}$ argue that there are temporal correlations in the occurrence of hazardous material pipelines incidents and this might be a useful consideration when creating contingency plans for large-scale pipeline projects, such as the one considered in Cyprus. Kuwari and Kaiser $(2011)^{12}$ used satellite images to monitor land use changes at Al Khore, a region in Qatar where a natural gas field was discovered. Their analysis focused on the investigation of rapid urbanization rate and its effects on other land uses at Al Khore city and the impact of Ras Laffan harbor on the coastline. The paper "Quantitative risk analysis of urban natural gas pipeline networks using geographical information systems" presents a novel quantitative risk analysis process for urban natural gas pipeline networks using geographical information systems ${ }^{13}$. The proposed method in paper "Risk assessment along the gas pipelines and its application in urban planning" has a certain theoretical and practical significance in establishing and improving risk analysis along the gas pipeline and urban land-use planning ${ }^{14}$. The results of paper "QUANTITATIVE ASSESSMENT OF ENVIRONMENTAL RISK DUE TO ACCIDENTAL
SPILLS FROM ONSHORE PIPELINES" confirmed that the proposed model may be considered an important tool within a comprehensive approach to the management of risk related to onshore pipeline ${ }^{15}$. The results of paper "Developing a new fuzzy inference system for pipeline risk assessment" demonstrate that the proposed model provides more accurate, precise, sure results; so that, it can be taken into account as an intelligent risk assessment tool in different engineering problems ${ }^{16}$. The paper "Fuzzy Risk Modeling of Process Operations in the Oil and Gas Refineries" proposes a model for the risk of the process operations in the oil and gas refineries ${ }^{17}$.

In terms of political divisions, this project is located in the city of Ahar, Harris and Bostanabad of East Azarbaijan. The gas transmission pipeline started from Duzduzan. Longitude with 4,203,000 681,000 latitude and it started in Ahar longitude gas satation and ends in the latitude of $4,257,000$ 679,500 .

The study area begins from Duzduzan and passed from the towns and villages such as; Rajol abad, Zaranq, Barough, Kalhor ,Torkayesh and finally ends near Ahar.

The second gas supply line Duzduzan Ahar approximate length of $60 \mathrm{~km}$ and a diameter of 20 inches from the CGS station Duzduzan been split from an existing 30 inch line parallel to the existing 10-inch natural gas transmission pipeline continues to AHAR. The climate of province is cold. Two systems for climate studies are modified. Maarten, two Maarten, Ambrzhh, and Sylyanynf are considerate to be given a different picture of climate.

Precipitation Rainfall data for all selected network stations in a 26-year period (1966-67 to 1991-92) shows the coefficient of variation of rainfall changing from $9 / 19$ in Julfa to $1 / 44$ of the Vanyar. Structural classification of precipitation, the area of the northern and central zones of Azerbaijan and part of the sedimentary basin also includes the Magi. From the perspective of regional tectonic earthquake central Iranian province covering the Precambrian organic phases, Middle Triassic, Late Cretaceous, Eocene-Late Miocene and Pliocene 
phase is fundamental. Pliocene and Quaternary tectonics of the region between Central Iran and Zagros continental collision tectonic implications of the Quaternary faulting, and seismicity of the volcano Sahand and Shilan results continue to reflect the current pressures of organic zone. The route also crosses with no regions with any protective value. Relatively far from the only geological value of the project is located.

The main fauna are, fox, jackal, wolf, hedgeohog, porcupine, hare, otter, wild boar, bear, bat, altitude sheep and goats, and birds such as kill, Common Crane, green cassock, geese, ducks, swallows, sparrow hawk, slab, eagles and barbary falcon, and .... .

The most important plant species are, acanthophyllum, wild almond, juniper, poplar, Stipa, and .... .

\section{MATERIALS AND METHODS}

The main methods to perform EIA in the world are the matrix of explanatory checklist on the synthesis and analysis system (Canter, 1996) ${ }^{18}$.
This method has been used to explain the effects and consequences of environmental projects. Alongside this method is evaluated using , due to its advantages in Holistic together as well as providing the overall vision of the environmental consequences of a project be very useful:. For this reason, in this study the evaluation matrix for the analysis of the environmental impacts of the project will be used. In this context, we first complete a checklist of important environmental consequences Duzduzan _ Ahar pipeline physical environment, biological, socio economic and land use study area is presented.

\section{RESULTS AND DISCUSSION}

\section{Summary and analysis of the design matrix}

In The construction phase 19 micro activities have evaluated in front of about 12 environmental factors (in the various environments). As the table shows, activities such as; excavation, embankment and excavation show the greatest negative impact on the whole environment of area. And the most important activity with positive effects on the aforementioned factors is manpower recruitment. The effect of different micro-environmental factors

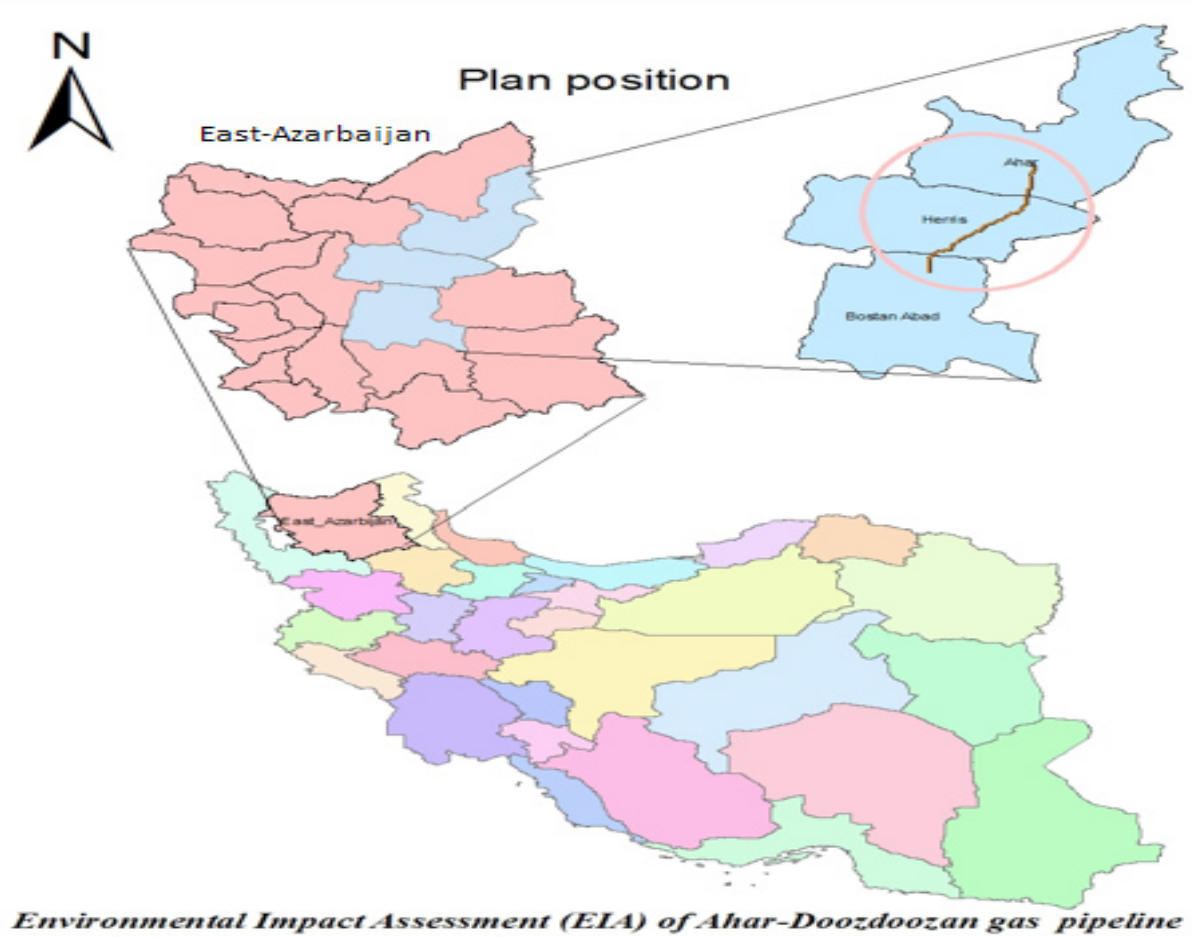

Fig. 1: Project location map 







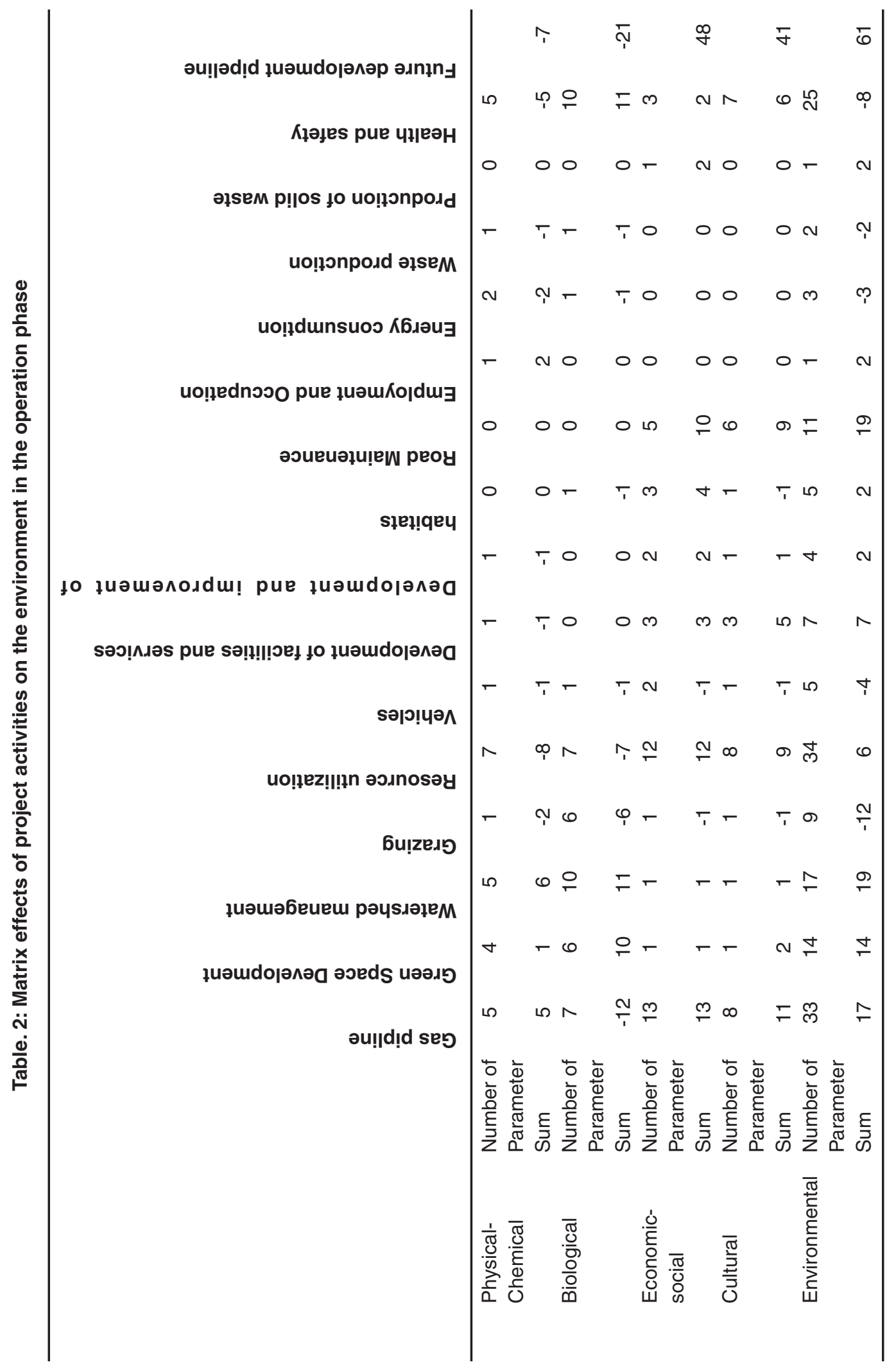




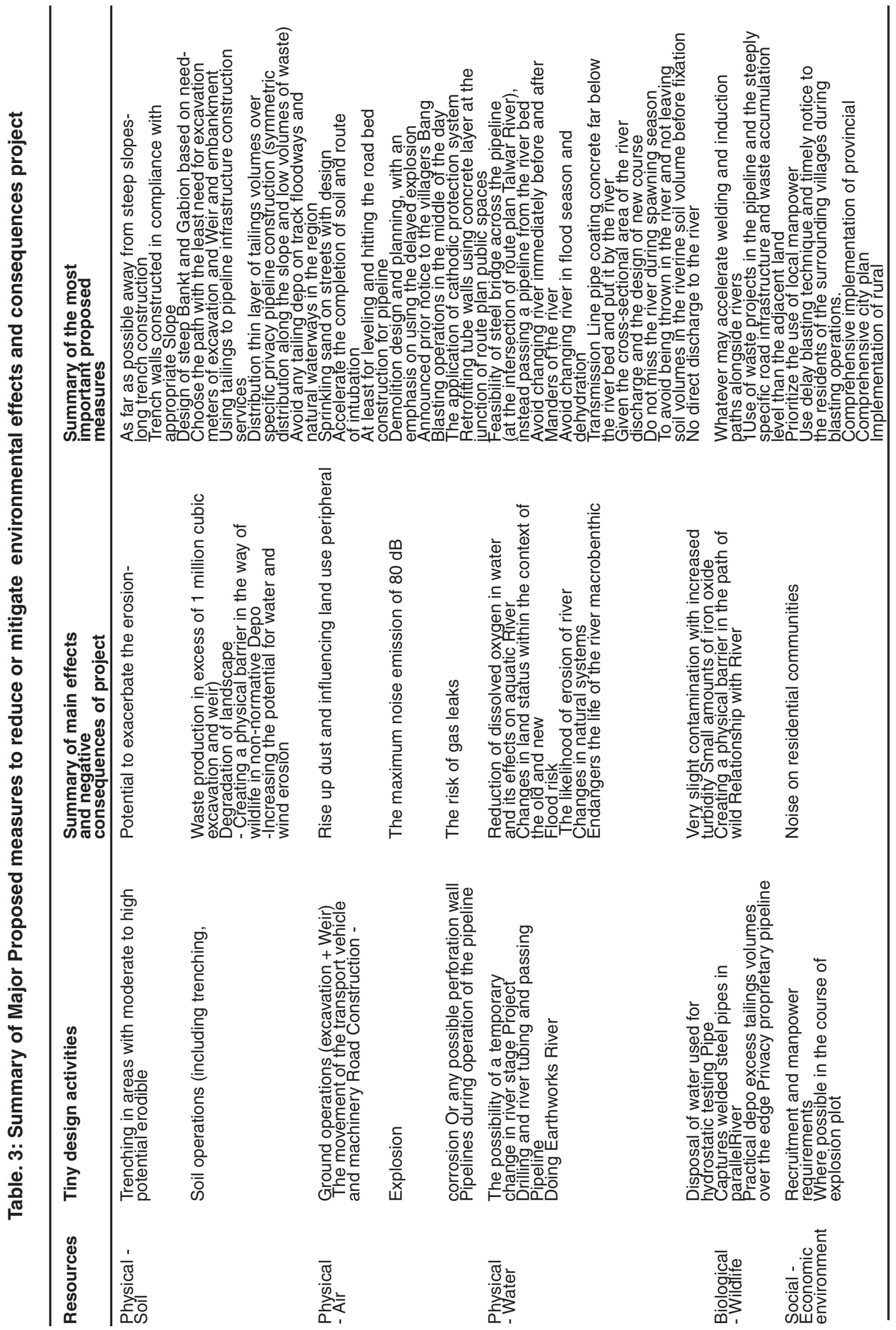


is presented in the tables, why should refrain from further elaboration.

In the operation phase 15 micro activities have evaluated in front of about 15 environmental factors (in the various environments). As Shown in Table 2 operation phase activities such as; grazing, vehicle traffic and waste production can have negative effects. The effect of different microenvironmental factors are presented in the tables, why should refrain from further elaboration.

In any case, it must be said that the most important activities with negative impacts in the construction phase of the project on environmental factors considered, including drilling and blasting, Digging route, and the most important activities of the positive effects of phase on the factors, manpower recruitment.

In the process of implementation and operation of the Project or any component part of the highly negative environmental impact of this project will not be under pressure, negative pressure design elements of environmental impact is almost is environment Range capacity tolerable. Most positive impact on environmental factors Income and welfare, employment levels, activities, services and commerce, immigration control and air quality. Operation phase of public works was positive that most of them involve the exploitation of gas or natural gas transportation and gas pipeline monitoring requirements.

According to the developed methodology it is necessary to use RS and GIS tools in the study current environment situation, routing environmental alternatives and make land use maps of transmission path. With regard to all issues presented in explanatory checklist of this project and also previous clauses from the standpoint of environmental compliance provisions there isn't any problem for implementation.

In general we can say that most negative effects of land use change within the immediate project plan. The most positive effects and consequences of the operation phase of the project will be divided into three levels, local, regional and national attributes.
Locally Duzduzan city, Harris, Ahar and all subsidiaries villages in the direction of a blessing gas pipeline benefit. In the construction industry in the years to come will enjoy the blessings of gas. On the other hand cleaner and cheaper fuel alternative fuels used by the inhabitants of the towns and villages will increase the positive impact of welfare, health and services in the area.

Income, welfare and health facilities Consequences are the positive aspects of the national plan cheap and clean fuel to replace fossil fuels such as natural gas, fuel oil and gas oil and returns. By replacing the fuel -saving large amounts on imports of derivatives are taken and instead use this valuable petrochemical derivatives and new products are added. All of these are consequences of the policy change is based on Ministry of Petroleum Exporting further develop and achieve selfsufficiency and economic profit is greater. Another positive outcome of the project at the regional level as well as the prevention and control of air pollution in cities due to the replacement of fossil fuels with clean fuel gas path will be will see.

One of the objectives of the national land policy and fair distribution of wealth, industry and the general development of facilities to suit the whole country. This project is one of the efficient and effective means to achieve this is important.

\section{CONCLUSIONS}

Gas pipeline uses a complex system to transport natural gas.importance of direct pipelines are different from indirect pipelines. To assess the effects of pipeline in two-stage of construction and operation we used a simple matrix method. Building effects in Environmental factors are short and temporal and with applying corrective solutions they can be minimized.

\section{The results of a simple matrix show that}

In the construction phase the most important activities with negative effects are considered in 19 environmental factors, including; excavation, embankment and excavation, and the most important activity with positive effect on the aforementioned factors, is manpower recruitment. Most positive impacts on environmental factors are 
revenue and welfare, employment levels, commerce and manning activities, immigration control and air quality.

In the Operation phase activities such as; grazing, vehicle traffic and wastewater production have negative effects. Most of this phase effects are positive which involve; exploitation of gas or natural gas transportation and gas pipeline monitoring.

During both project construction and operation phases, each micro activity in 19 environmental factors even won't have $30 \%$ of negative effects. Therefore, none of the micro activities of this project (either in the construction phase or operation phase) doesn't have negative effects on the environment.

Another important result of this study is obtaining reliable quantitative result from GIS and remote sensing. Land use maps derived from satellite images which are modified by field visit shows a double effects of using these systems.in these projects such as Gas pipeline projects, land use change in the area is inevitable. Accurate extraction of land use change extent is as an important part of the report, whiles the legal obligation of the Iran's Environmental Protection Agency is applied.

At the end risk assessment is recommended in this project which it's better to done with Kent Molbayer method. This project results shows that firstly; the precision of such studies is largely depends on the accuracy of the RS and GIS results. Secondly, it is impossible to do most parts of the EIA study without employing these systems. Therefore using RS and GIS in EIA linear studies as a basic, reliable and trustworthy can be suggested.

\section{REFRENCES}

1. Salehi Moayad, M., Karimi S., Enviromental impact assessment (EIA) of gas pipeline transmission in bijar with GIS and RS method, Int. J. Environ. Res 41, (2007).

2. Nasr, D., Massoud, M. A., Khoury, R. and Kabakian, V., Environmental impact of reconstruction activities: a case of Lebanon. Int.J.Environ.Res. 3(2), 301-308, (2009).

3. Paterson, W. M., Reid, H. E., Sears, S. K. and Morrow, J.M., Lights, camera approval? video in the environmental impact assessment process. Environ. Impact Asses. Rev., 13, 177-188, (1993).

4. Meredith, T. C., Environmental impact assessment, cultural diversity, and sustainable rural development. Environ. Impact Asses. Rev., 12, 125-138, (1992).

5. Hyman, E. L. and Stiftel, B., Combining Facts and values in Environmental Impact Assessment. Boulder, CoWestview, (1988).

6. Kanokporn, K., lamaram, V. Ecological Impact Assessment; Conceptual Approach for Better Outcomes. Int. J. Environ. Res., 5(2):435-446, (2011).

7. Jafari, H., Lotfi A., Enviromental impact assessment of Oil biological activities in Persian Gulf, Int. J. Environ.Res 34, (2004).
8. Transmission gas pipeline south stream on the territory of the republic of Bulgaria, Environmental impact assessment report, (2013).

9. Jozi. S. A., Iran khahi.M., Environmental Risk Assessment of Gas pipelines by using of AHP Combined Method, Journal of Environmental Studies, 53, (2010).

10. Papadopoulou, M. P., \& Antoniou, C., Environmental impact assessment methodological framework for liquefied natural gas terminal and transport network planning. Energy Policy, 68, 306-319, (2014).

11. Sosa, E., Alvarez-Ramirez, J., Timecorrelations in the dynamics of hazardous material pipelines incidents. J. Hazard. Mater. , 1204-1209, (2009).

12. Al Kuwari, N. Y., and M. F. Kaiser. "Impact of North Gas Field development on landuse/ landcover changes at Al Khore, North Qatar, using remote sensing and GIS." Applied Geography 31, no. 3(2011): 1144-1153.

13. Ma, L., Cheng, L., \& Li, M., Quantitative risk analysis of urban natural gas pipeline networks using geographical information systems. Journal of Loss Prevention in the Process Industries, 26(6), 1183-1192, 
(2013).

14. Zhou, Y., Hu, G., Li, J., \& Diao, C. Risk assessment along the gas pipelines and its application in urban planning. Land Use Policy, 38, 233-238, (2014).

15. Bonvicini, S., Antonioni, G., Morra, P., \& Cozzani, V., Quantitative assessment of environmental risk due to accidental spills from onshore pipelines. Process Safety and Environmental Protection, (2014).

16. Jamshidi, A., Yazdani-Chamzini, A., Yakhchali, S. H., \& Khaleghi, S. Developing a new fuzzy inference system for pipeline risk assessment. Journal of Loss Prevention in the Process Industries, 26(1), 197-208, (2013).

17. Sa'idi, E., Anvaripour, B., Jaderi, F., \& Nabhani, N., Fuzzy Risk Modeling of Process Operations in the Oil and Gas Refineries. Journal of Loss Prevention in the Process Industries, (2014).

18. Canter, L. W. Environmental Impact Assessment. Mc Grew Hill Book Co. Baltimore, (1996). 